\title{
Fuzzy Modelling for Predicting the Risk of Recurrence and Progression of Superficial Bladder Tumors
}

\author{
Laércio L. Vendite, Kenia D. Savergnini, Ubirajara Ferreira, Wagner E. Matheus \\ Unicamp, Campinas, Brazil \\ Email:vendite@ime.unicamp.br, kenia@ime.unicamp.br, ubirafer@uol.com.br,wematheus@uol.com.br
}

How to cite this paper: Vendite, L.L., Savergnini, K.D., Ferreira, U. and Matheus, W.E. (2018) Fuzzy Modelling for Predicting the Risk of Recurrence and Progression of Superficial Bladder Tumors. Applied Mathematics, 9, 1091-1103.

https://doi.org/10.4236/am.2018.910074

Received: August 10, 2018

Accepted: October 12, 2018

Published: October 15, 2018

Copyright (c) 2018 by authors and Scientific Research Publishing Inc. This work is licensed under the Creative Commons Attribution International License (CC BY 4.0).

http://creativecommons.org/licenses/by/4.0/

\begin{abstract}
Nowadays, bladder cancer is the fourth most common cancer in adults and the second most frequent urogenital tumor. Predicting recurrence and progression of superficial bladder tumors, with available clinical information to decide the therapy to be used is a difficult task. In this work, two mathematical models were developed to help specialists on the decision process. The mathematical tool used to formulate the model was the fuzzy sets theory, due to its capacity in dealing with uncertainties inherent in medical concepts. In the first model, Stage, Grade and Size of the tumor were also considered input variables and Risk of Recurrence of a superficial bladder tumor as output variable of the first Fuzzy Rule-Based Systems (FRBS). In the second model, in addition to the Stage, Grade and Size of the tumor, it was also considered as input variable of a second FRBS Carcinoma in situ and, the Risk of Progression of superficial tumors as an output variable. For each model, simulations were made with data originated from of patients of the Clinics Hospital/UNICAMP and A. C. Camargo Hospital of São Paulo, with the aim to verify the reliability of results generated by the two systems. From a database and the possibility found by FRBS, after the possibility-probability transformation, we can generate the real probability of each fuzzy output set.
\end{abstract}

\section{Keywords}

Bladder Cancer, Fuzzy Modelling, Recurrence Risk, Progression Risk

\section{Introduction}

Cancer is a serious public health problem in developed and developing countries, accounting for more than six million deaths every year, and represents 
about $12 \%$ of all causes of death in the world.

In Brazil, cancer is the third most common cause of death, behind only circulatory diseases and external causes, thus being the second most common cause of death by disease.

The bladder, located at the bottom of the abdomen, just above and behind the pubic bone, is a hollow organ that stores urine produced by the kidneys, after the filtration of the blood, removing unnecessary substances for the functioning of the body.

Bladder cancer is the second most common tumor of the urinary tract, being preceded only by prostate cancer [1]. According to [2], it is the fourth most common cancer among men and the eighth most frequent tumour type for the female population.

Depending on the depth of invasion of the tumor in the bladder wall, the cancer is divided into superficial and invasive. The cancer is limited to a superficial tissue layer that lines the bladder invasive urothelial called while already penetrated at least the muscular layer of the bladder wall.

Staging is a classification process, which consists in assessing the extent of the disease, and is essential for the therapeutic planning and understanding of the prognosis of the patient. The TNM system-2002 of the International Union against cancer (UICC) is currently the most used to sort the staging. Table $1 \mathrm{de}$ scribes part of the TNM classification that we use in the models.

The histological grade of tumors is based on the degree of differentiation of tumor cells; i.e., it refers to a greater or lesser similarity of tumor cells with respect to normal original tissue. Currently the histological degree is classified either as low (when there are well differentiated cells which are less aggressive and rarely shows some progress) or high degree (when there are few differentiated cells, which, nonetheless are higher chance of recurrence, and are more aggressive).

About $70 \%$ of the cases of bladder cancer are diagnosed initially as superficial disease [1]. Superficial bladder tumors account for about $70 \%$ of cases, being that more than $80 \%$ remain confined to the mucosa or submucosa. However, it must be always subjected to a continuous and prolonged follow-up to detect recurrence and prevent progress.

Table 1. Staging System-TNM System (2002).

\begin{tabular}{cc}
\hline Stage & Description \\
T0 & Absence of primary tumor \\
Ta & Noninvasive papillary carcinoma (limited to mucosa) \\
Tis & Carcinoma in situ \\
T1 & Tumor invading subepithelial (invasion of the lamina propria) \\
T2 & Tumor with muscle invasion \\
T3 & indicates lesions that involve perivesical fat \\
T4 & Tumor invades adjacents organs \\
\hline
\end{tabular}


Transurethral resection (TUR) of the tumor is the initial treatment aimed at the diagnosis and curative treatment [3]. During TUR, the tumor is removed in to the muscle layer of the bladder. A combination of different therapies including surgery, radiotherapy, chemotherapy or immunotherapy can be used to fight bladder cancer.

\section{Objectives}

Bladder cancer is the second most common type of tumor of the urinary tract, but through appropriate measures of prevention and early detection, we can diagnose these tumors in the early stages, achieving cure for over $70 \%$ of the cases, with a proper treatment. Our goal is to apply the fuzzy theory to predict the risk of recurrence and progression of superficial bladder tumors, with available clinical information to decide the therapy to be used. Two mathematical models were developed to help specialists on the decision process.

In the first model, Stage, Grade and Size of tumor were also considered input variables and Risk of Recurrence of a superficial bladder tumor as output variable of the first Fuzzy Rule-Based Systems (FRBS), that is, the possibility of a bladder tumor recurrence that was in the Ta or T1 stage. In the second model, in addition to the Stage, Grade and Size of the tumor, it was also considered as input variable of a second FRBS Carcinoma in situ and as a output variable, the Risk of Progression of superficial tumor, that is, the possibility of a bladder tumor progression that was in the $\mathrm{T} 2, \mathrm{~T} 3$ or $\mathrm{T} 4$ stage.

\section{Fuzzy Model}

The fuzzy set theory is a new mathematical tool to study indeterminacy phenomena, especially subjective estimation or expert data. Up to now, Fuzzy Sets theory has been developed to a fairly complete system and has considerable achievements in both theoretical aspect and practical aspect [4]. To explore the recent developments of uncertainty theory, the interested readers may consult the book of [5].

The mathematical tool used to formulate the model was the Fuzzy Sets theory that was proposed by [6], due to its capacity en dealing with uncertainties inherent in medical concepts.

A fuzzy system rule-based (FRBS), is composed of four main modules:

1) The encoder (or fuzzification) that represents the input and output variables of the system, by fuzzy sets;

2) A rule base;

3) An inference method;

4) The decoder (or defuzzification) which transforms the output, that is a fuzzy set, in a numeric value [7] [8].

\subsection{Model 1-Risk of Recurrence}

In this fuzzy model, the input variables considered were: 
- The Stage, designed by as Ta and T1, according to the TNM system, and translated by fuzzy sets;

- The Histological Grade, rated as either low or high;

- The Size, that indicates the size of the tumor, classified in three typrs: less than $1.5 \mathrm{~cm}, 1.5$ to $3 \mathrm{~cm}$ and greater than $3 \mathrm{~cm}$.

Figure 1 represents the basic structure of model 1 and Figures 2-4 represent the membership function of fuzzy sets given by input variables.

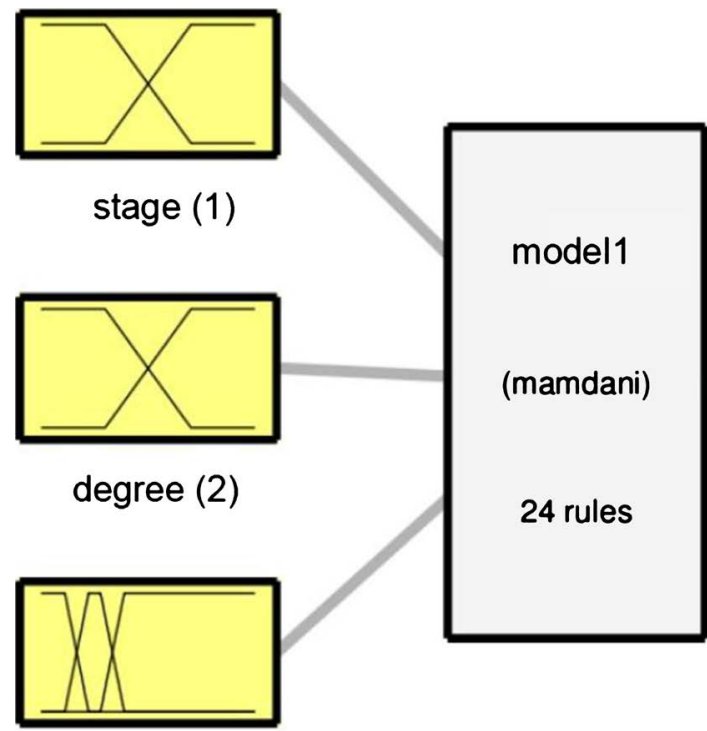

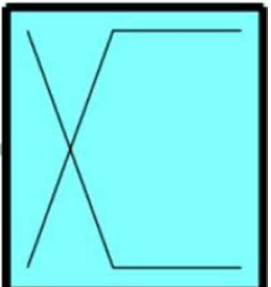

recurrence-risk (2)

size (3)

System modelo1: 3 inputs, 1 outputs, 24 rules

Figure 1. Model 1-Risk of Recurrence.

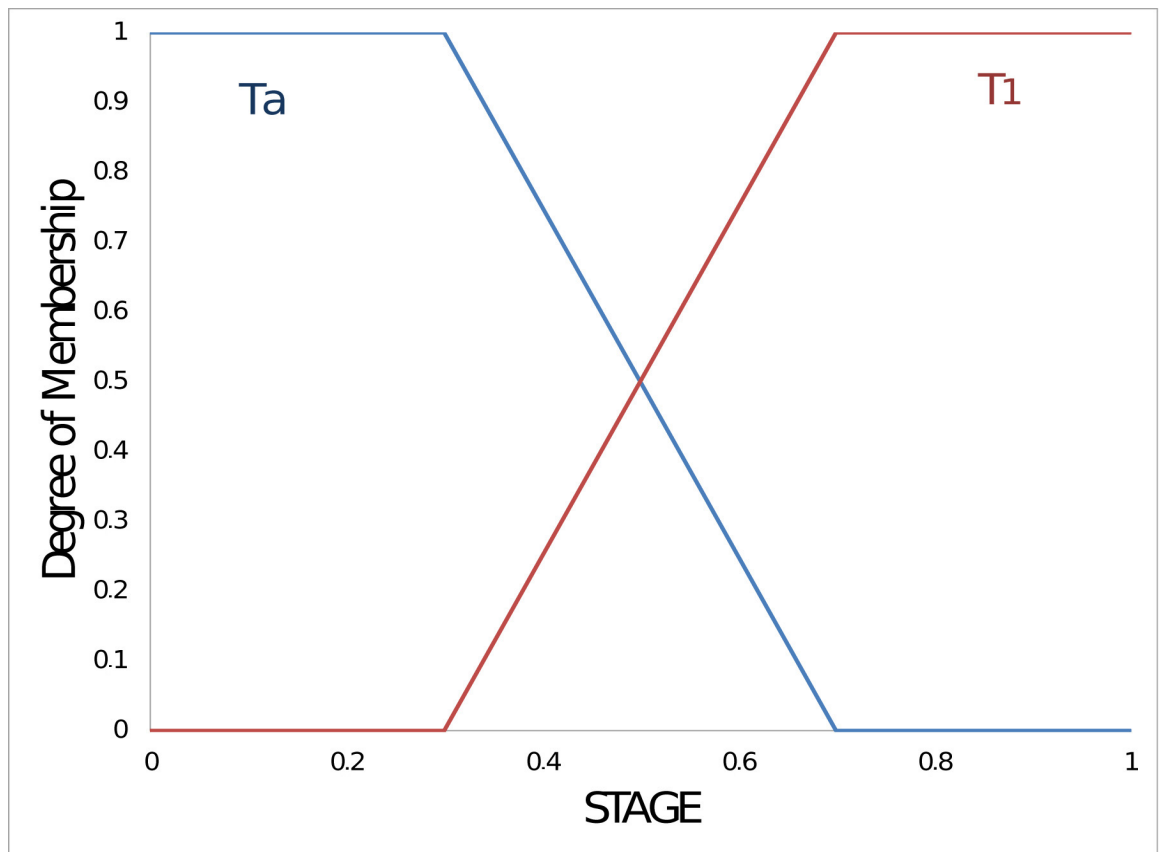

Figure 2. Stage. 


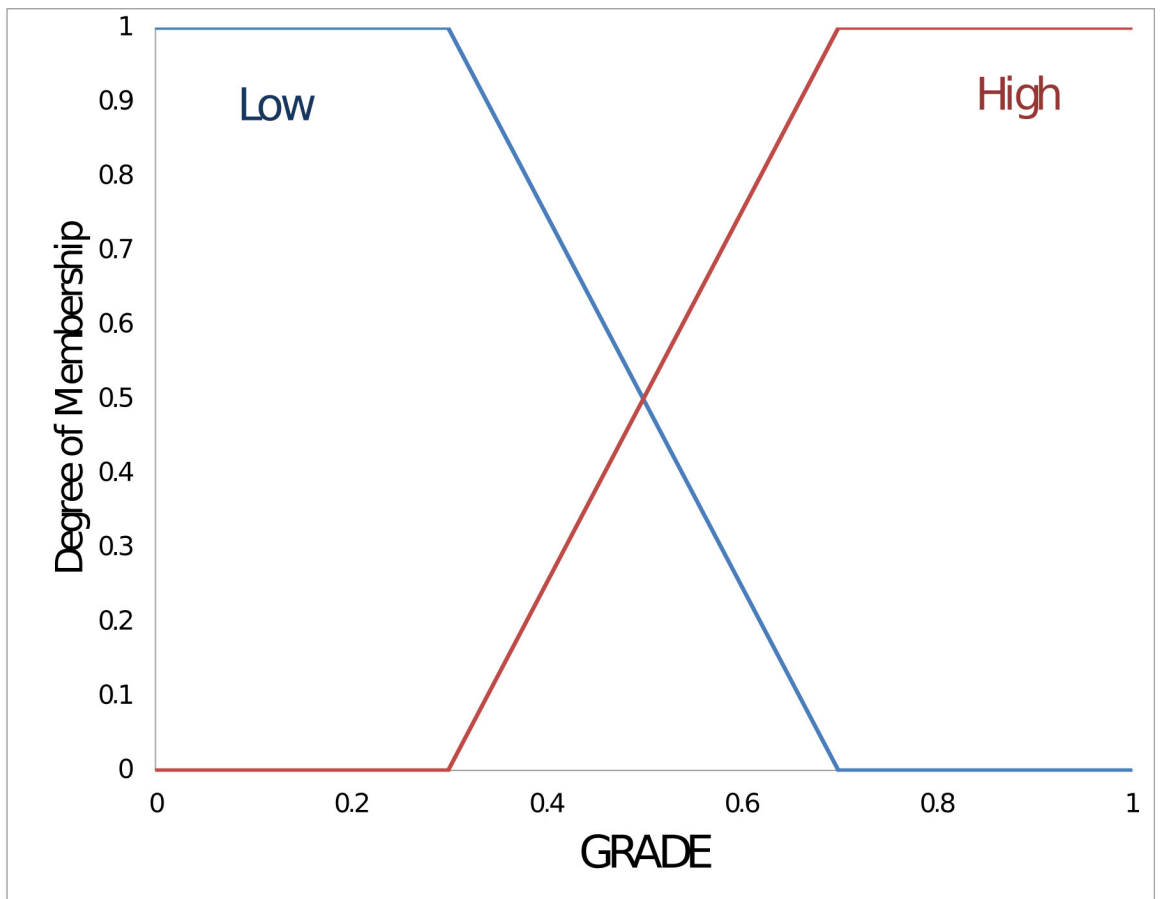

Figure 3. Histological grade.

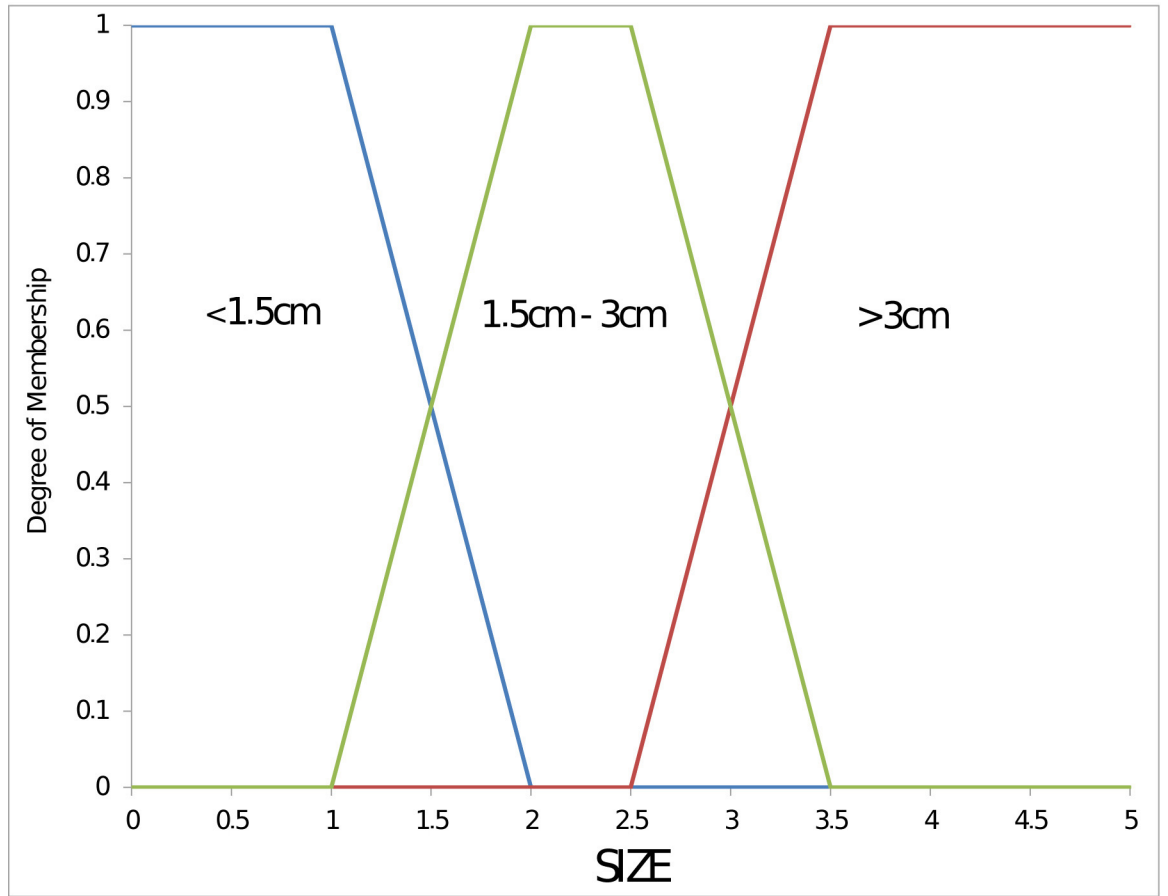

Figure 4. Size.

The output variable "Risk of Recurrence" can assume the following linguistic values; the following linguistic terms: recurrence less than 3 years and recurrence greater than 3 years. For the domain of this variable we consider the range [0 10] as shown in Figure 5. The choice of format of functions was a kind of "kick starting" and after analyzing the results, the format of these functions are 
changed in order to improve the output of the system.

The next step is the creation of the rule base that is made with the help of an expert. To build the rules we made all the different combinations of input variables (stadium, histologic grade and size) and output variables (risk of recurrence). Some rules can be found in Table 2 .

In this fuzzy model, the some rules considered were:

- Stage is Ta, Histological Grade is low and Size is $1.5-3 \mathrm{~cm}$ then the Risk of Recidive is $<3$ years.

- If Stage is Ta, Histological Grade is high and Size is $>3 \mathrm{~cm}$ then the Risk of Recidive is $<3$ years.

- If Stage is T1, Histological Grade is low and Size is $<1.5 \mathrm{~cm}$ then the Risk of Recidive is $>3$ years.

- If Stage is T1, Histological Grade is high and Size is $1.5-3 \mathrm{~cm}$ then the Risk of Recidive is $<3$ years.

- If Stage is T1, Histological Grade is high and Size is $>3 \mathrm{~cm}$ then the Risk of Recidive is $>3$ years.

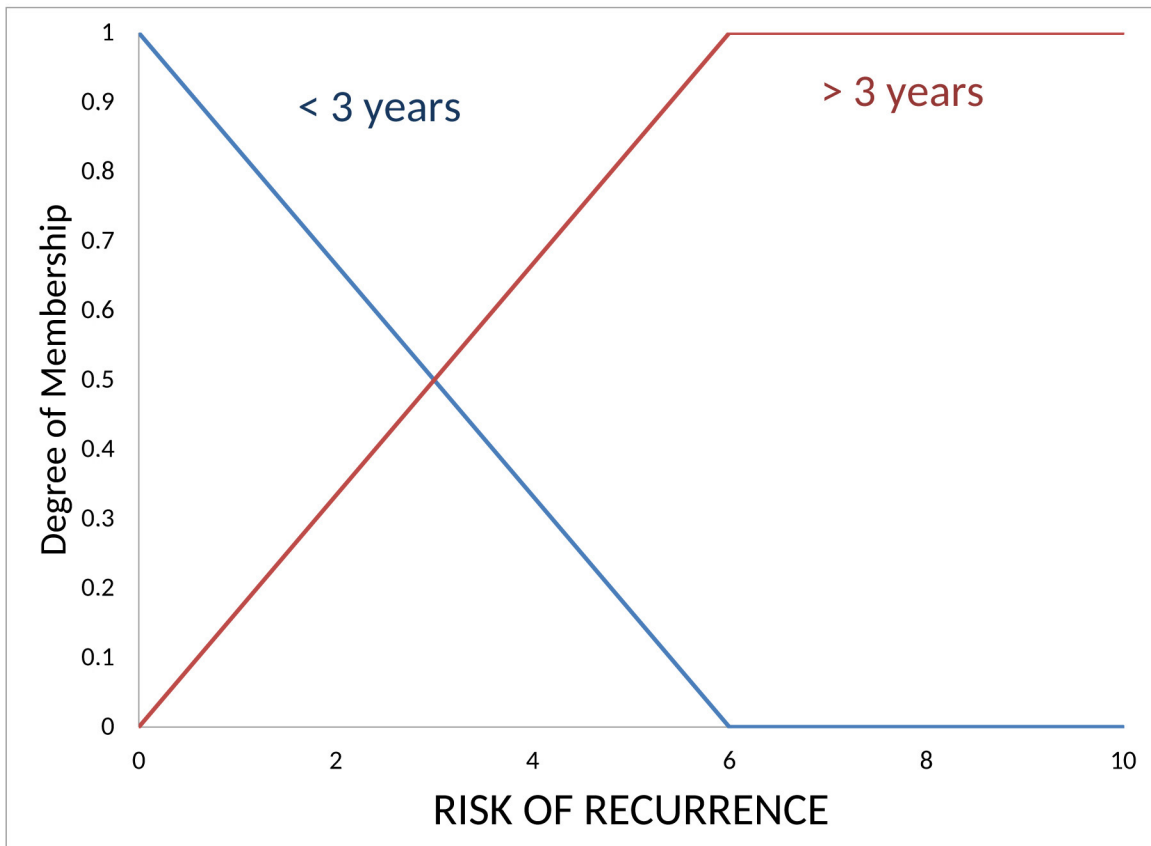

Figure 5. Risk of recurrence.

Table 2. Some of the 24 rules.

\begin{tabular}{cccccc}
\hline $\mathbf{N}$ & Stage & Histological Grade & Size & Risk of Recidive & Weight \\
\hline 3 & Ta & low & $1.5-3 \mathrm{~cm}$ & $<3$ years & 0.54 \\
11 & Ta & high & $>3 \mathrm{~cm}$ & $<3$ years & 0.78 \\
14 & T1 & low & $<1.5 \mathrm{~cm}$ & $>3$ years & 0.4 \\
21 & T1 & high & $1.5-3 \mathrm{~cm}$ & $<3$ years & 0.8 \\
24 & T1 & high & $>3 \mathrm{~cm}$ & $>3$ years & 0.1 \\
\hline
\end{tabular}


After the rule base completed, we need to translate it mathematically by means of approximate reasoning techniques. For this, the inference method used will be the Mamdani method. The defuzzification of the fuzzy sets, that represents the output of the system, will be made by the method of center of gravity, so that, the find result is a real number.

\subsection{Simulation Model 1}

We made some model simulations, with actual data of patients from Hospital das Clínicas UNICAMP and A. C. of São Paulo, using the membership function of the output variable. The results obtained by the patient's possibility FRBS relapse in less and after three years. Such results were transformed into probabilities and proved to be somewhat pessimistic.

Given this, we adapt the membership function which describes the output of the system, adjusting a curve (by the method of least squares). Figure 6 shows the graphic of the previously obtained function.

Using same functions, other simulations were made taking into account the data. Some of the results that we obtained are shown in Table 4 in terms of possibility, probability and likelihood of the actual case. The possibility was obtained from the fuzzy system; the probability was calculated by transforming the possibility - probability. The probability calculation of real case was calculated as follows: divide the 170 patients from the two hospitals into four groups (depending on the behavior of each of them) and, for each group, we calculate the percentage of recurred cases.

Table 3 shows how the division of the groups was made and the percentage

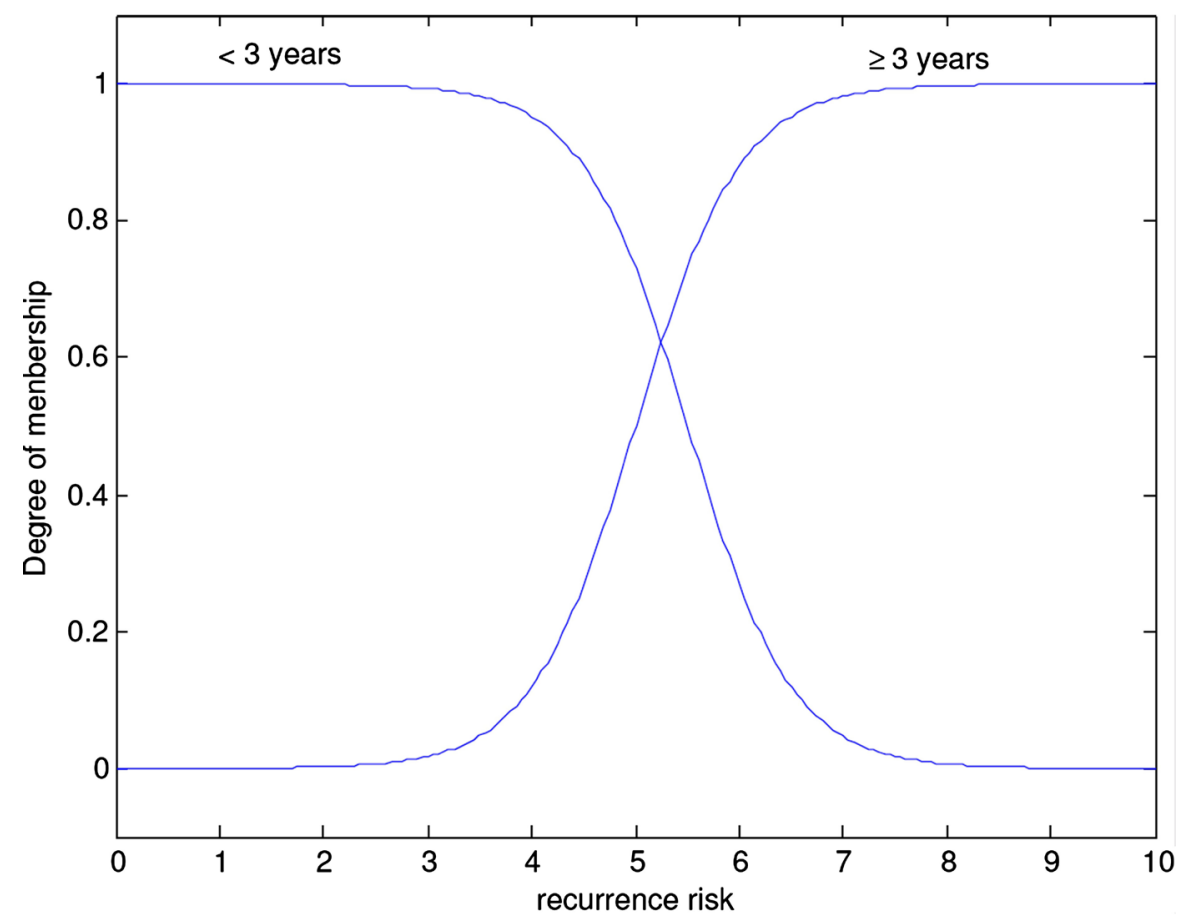

Figure 6. Membership function function set assumed by the recurrence risk variable. 
of each group.

So, we calculate the probability of a real case as the product between the probability resulting from the transformation possibility-probability, and the percentage of Table 3. This calculation was necessary because it considered only the probability of the transformation; we would be taking into account that all 170 patients had relapsed, which does not happen.

For Table 4 we note that, in all cases, the probability of recurrence is always greater for the Risk of Recurrence set less than 3 years, with values very close to that of the set of Risk of Recurrence greater than 3 years when the tumor is in stage $\mathrm{Ta}$ and has low grade, and greater in the case of a tumor at $\mathrm{T} 1$ and high degree.

Also it was noticed a worsening of the clinical picture of patients with change of Stadium (from Ta to T1) and with the change of histological grade (from low

Table 3. Recurred's percentage.

\begin{tabular}{cccc}
\hline Group & Stage & Histological Grade & Percentage \\
\hline I & Ta & low & $31 \%$ \\
II & Ta & high & $43 \%$ \\
III & T1 & low & $29 \%$ \\
IV & T1 & high & $44 \%$ \\
\hline
\end{tabular}

Table 4. Some output risk obtained by new FRBS.

\begin{tabular}{|c|c|c|c|c|}
\hline Patient & Recurrence & Possib. & Probab. & Real Case \\
\hline Stage $\mathrm{Ta}$ & $<3$ years & 0.53 & $52 \%$ & $16 \%$ \\
\hline Low Grade & $>3$ years & 0.49 & $49 \%$ & $15 \%$ \\
\hline \multicolumn{5}{|l|}{ Size $1.5 \mathrm{~cm}$} \\
\hline Stage Ta & $<3$ years & 0.54 & $54 \%$ & $17 \%$ \\
\hline Low Grade & $>3$ years & 0.46 & $46 \%$ & $14 \%$ \\
\hline \multicolumn{5}{|l|}{ Size $3 \mathrm{~cm}$} \\
\hline Stage $\mathrm{Ta}$ & $<3$ years & 0.77 & $77 \%$ & $33 \%$ \\
\hline High Grade & $>3$ years & 0.23 & $23 \%$ & $10 \%$ \\
\hline \multicolumn{5}{|l|}{ Size $5 \mathrm{~cm}$} \\
\hline Stage $\mathrm{T} 1$ & $<3$ years & 0.65 & $65 \%$ & $19 \%$ \\
\hline Low Grade & $>3$ years & 0.35 & $35 \%$ & $10 \%$ \\
\hline \multicolumn{5}{|l|}{ Size $1.7 \mathrm{~cm}$} \\
\hline Stage T1 & $<3$ years & 0.75 & $76 \%$ & $33 \%$ \\
\hline High Grade & $>3$ years & 0.24 & $24 \%$ & $11 \%$ \\
\hline \multicolumn{5}{|l|}{ Size $0.9 \mathrm{~cm}$} \\
\hline Stage $\mathrm{T} 1$ & $<3$ years & 0.85 & $85 \%$ & $37 \%$ \\
\hline High Grade & $>3$ years & 0.15 & $15 \%$ & $7 \%$ \\
\hline Size $7 \mathrm{~cm}$ & & & & \\
\hline
\end{tabular}


to high) and therefore the increased likelihood of the actual case in the Risk of Recurrence set less than 3 years and an increased likelihood in the Risk of Recurrence set greater than 3 years.

In the assessment of experts Dr. Ubirajara Ferreira and Dr. Eduardo Wagner Matheus from the Faculty of Medical Sciences at Unicamp, the results obtained with the new membership function function were more optimistic and so were considered to be more consistent with the clinical reality faced by patients.

\subsection{Model 2-Risk of Progression}

The variables chosen for this model are the same as for the previous model, adjoined by another variable: Carcinoma in situ (Cis) that worsens the prognosis of patients. In this model, the input variables of the system were chosen as: Stage, Histological Grade, Size and Cis and the system output variable Risk of Progression as shows Figure 7.

The linguistic terms and membership function assigned to the variables Stage, Histological Grade e Size were the same used in model 1. Then, the Stage was classified as Ta and T1, the variable Histological Grade was classified as low and high and the variable Size in the following terms: less than $1.5 \mathrm{~cm}, 1.5-3 \mathrm{~cm}$ and greater than $3 \mathrm{~cm}$.

For superficial bladder tumor, the prognosis is generally favorable, but worsens with the presence of Carcinoma in situ (Cis). The variable Cis was classified as Absence and Present.

The membership function for the input variables is presented in Figures 2-4 and Figure 8.

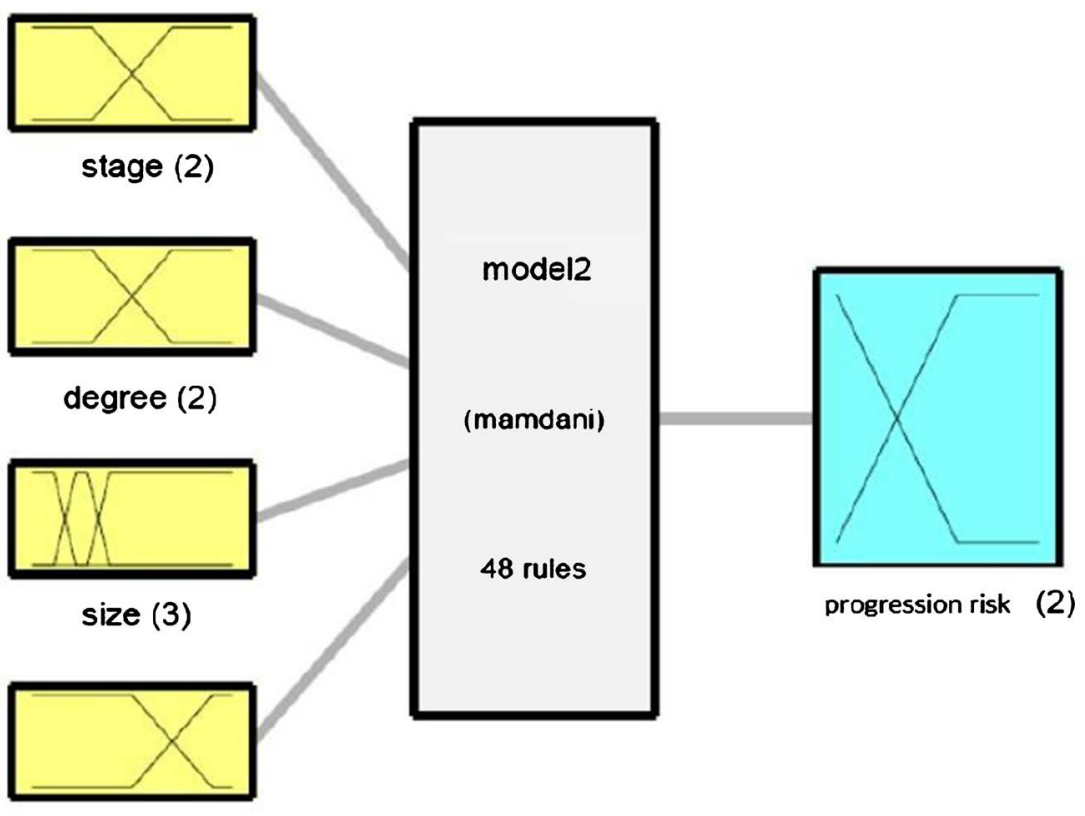

$\operatorname{cis}(2)$

System modelo2: 4 inputs, 1 outputs, 48 rules

Figure 7. Model 2-Risk of Progression. 
The output variable of the system Risk of Progression was considered as Progression less than 3 years and Progression greater than 3 years. The range of this variable is [0 - 10], a choice based on patient data. Figure 9 illustrates the relevance of fuzzy sets.

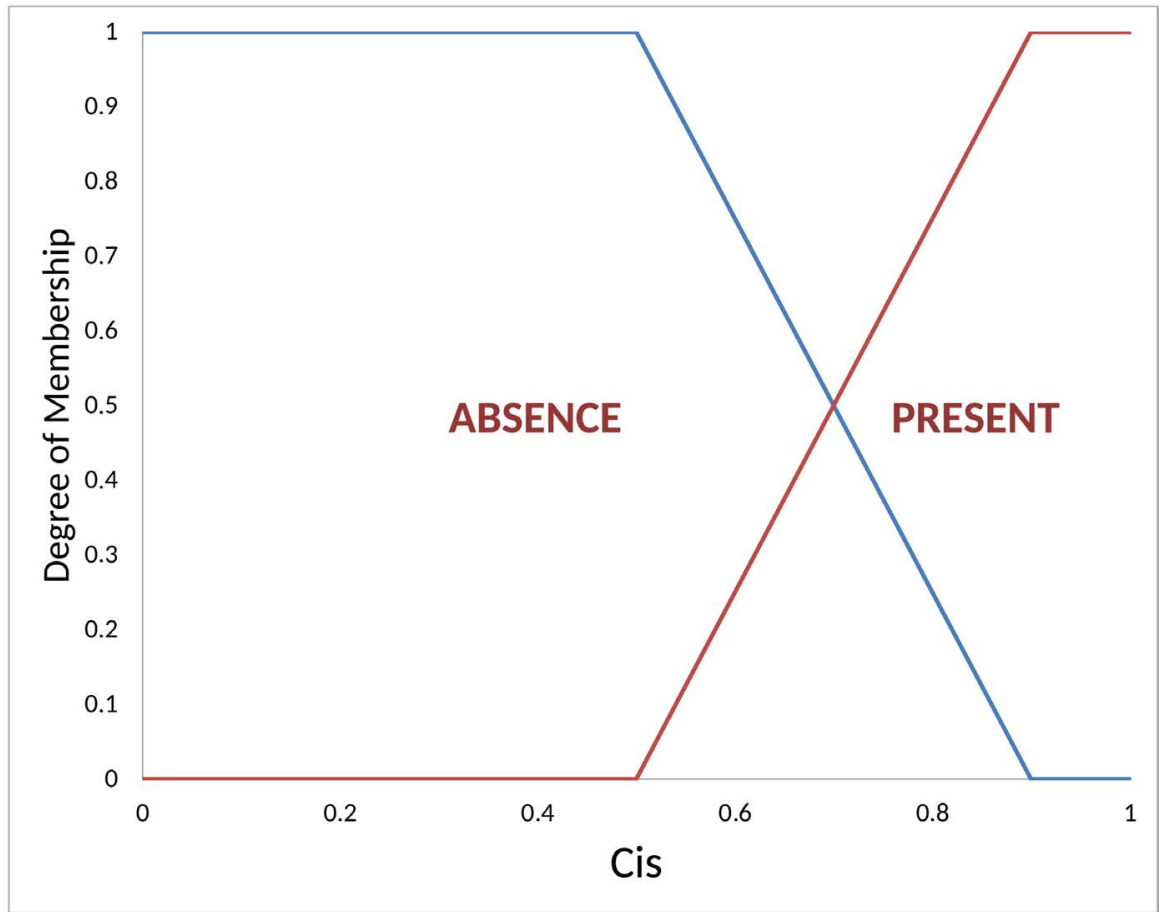

Figure 8. Carcinoma in situ.

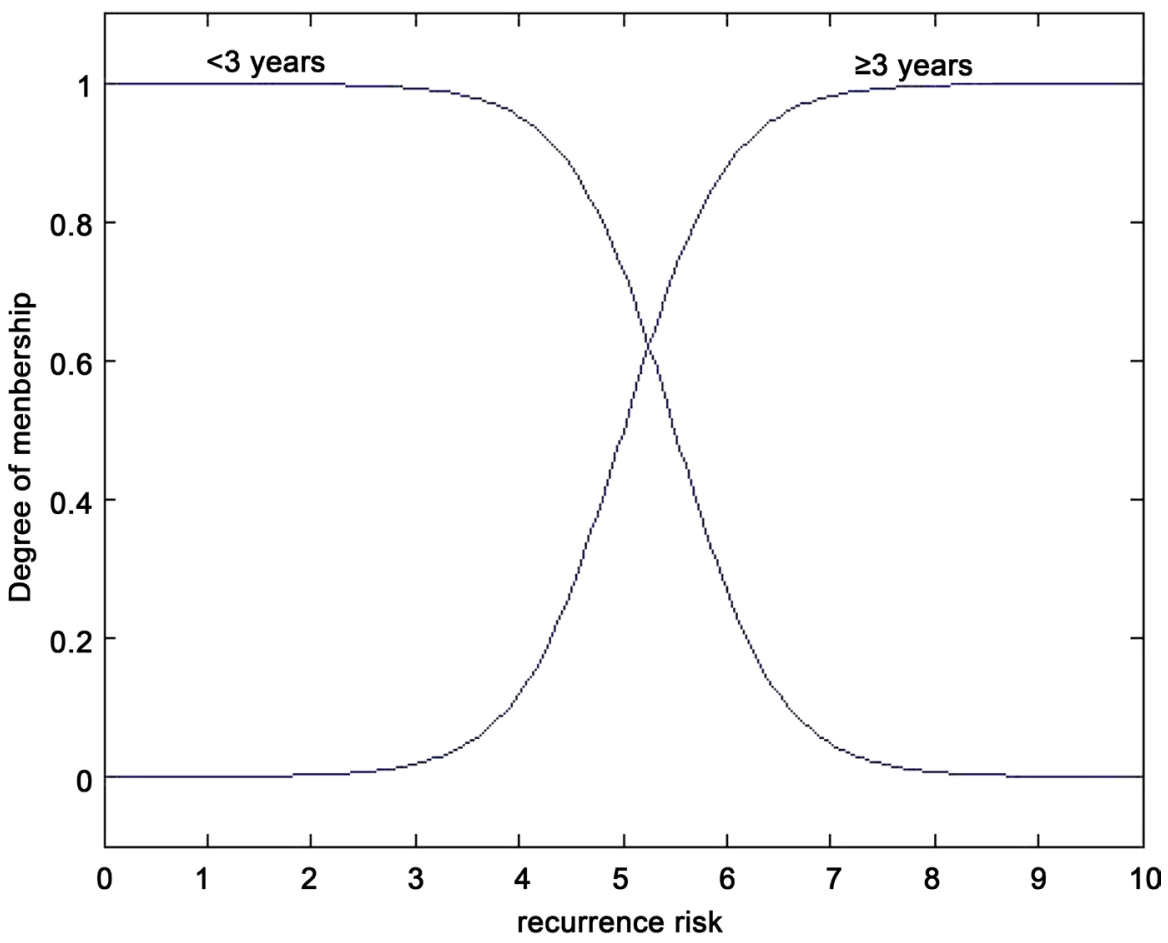

Figure 9. Membership functions of fuzzy sets assumed by the risk of progression. 
To build the base of rules, it was used all the possible combinations of input variables Stage, Histological Grade, Size and Cis and the output variable Risk of Progression taking into account the linguistic terms, allocated to each of these variables. Table 5 is part of the rule base.

In this fuzzy model 2, the some rules considered were:

- Stage is Ta, Histological Grade is low and Size is $<1.5 \mathrm{~cm}$, Cis is absent then the Risk of Progression is $<3$ years.

- Stage is Ta, Histological Grade is low and Size is $1.5-3 \mathrm{~cm}$, Cis is absent then the Risk of Progression is $>3$ years.

- Stage is Ta, Histological Grade is high and Size is $>3 \mathrm{~cm}$, Cis is absent then the Risk of Progression is $<3$ years.

- Stage is T1, Histological Grade is low and Size is $1.5-3 \mathrm{~cm}$, Cis is absent then the Risk of Progression is $>3$ years.

- Stage is T1, Histological Grade is low and Size is $<1.5 \mathrm{~cm}$, Cis is absent then the Risk of Progression is $<3$ years.

- Stage is T1, Histological Grade is high and Size is $<1.5 \mathrm{~cm}$, Cis is absent then the Risk of Progression is $<3$ years.

- Stage is T1, Histological Grade is high and Size is $>3 \mathrm{~cm}$, Cis is present then the Risk of Progression is $>3$ years.

To assign weight to the rules, a multivariate analysis, linear regression method was performed in order to obtain a mathematical relationship between the input and the output variables, from which the rules were obtained. This analysis was necessary due the difficulty experimented by the experts to attribute weight to the rules.

The inference was also done by Mamdani method and the defuzzication by the method of Center of Gravity, like in the previous model.

\subsection{Simulation Model 2}

In order to verify the reliability of the results generated by the system, simulations were made with the same data (Clinical Hospital of UNICAMP and A.C. Camargo Hospital of São Paulo), using the membership function function shown in Figure 9.

The results were analyzed and proved to be very pessimistic. In order to improve the results of this model, we adapted the membership function that

Table 5. Some of the 48 rules.

\begin{tabular}{ccccccc}
\hline $\mathbf{N}$ & Stage & Histological Grade & Size & Cis & Risk of Prog. & Weight \\
\hline 1 & Ta & low & $<1.5 \mathrm{~cm}$ & absent & $<3$ years & 0.1 \\
34 & Ta & low & $1.5-3 \mathrm{~cm}$ & absent & $>3$ years & 0.88 \\
13 & Ta & high & $>3 \mathrm{~cm}$ & absent & $<3$ years & 0.47 \\
42 & T1 & low & $1.5-3 \mathrm{~cm}$ & absent & $>3$ years & 0.58 \\
17 & T1 & low & $<1.5 \mathrm{~cm}$ & absent & $<3$ years & 0.4 \\
25 & T1 & high & $<1.5 \mathrm{~cm}$ & absent & $<3$ years & 0.75 \\
32 & T1 & high & $>3 \mathrm{~cm}$ & present & $>3$ years & 0.13 \\
\hline
\end{tabular}


describes the fuzzy output variable's set. Figure 9 represents the membership function function for the fuzzy system output set, obtained through curves adjustments.

To assign weight to the rules, a multivariate analysis and linear regression method was performed in order to obtain a relation. Using these set of functions, new simulations were made. Some of the results that we obtained are shown in Table 7 in terms of possibility, probability and likelihood of the actual case. The probability of real case was calculated as in the previous model, however, this time, the group of 170 patients was divided into two groups (because progression rarely happens) and, for each group, we calculated the percentage of patients who have progressed. Table 6 shows how the division of the groups was done and the percentage of each were obtained.

Table 6. Percentage of patients who presented progression.

\begin{tabular}{ccc}
\hline Group & Hist. Grade & Percentage \\
\hline I & low & $4 \%$ \\
II & high & $10 \%$ \\
\hline
\end{tabular}

Table 7. Some results obtained by the new model 2 FRBS.

\begin{tabular}{|c|c|c|c|c|}
\hline Patient & Risk de Prog. & Possib. & Probab. & Real Case \\
\hline \multicolumn{5}{|l|}{ Stage Ta } \\
\hline Low Grade & $<3$ years & 0.08 & $7 \%$ & $0.3 \%$ \\
\hline Size $1.7 \mathrm{~cm}$ & $>3$ years & 0.93 & $93 \%$ & $3.7 \%$ \\
\hline \multicolumn{5}{|l|}{ Cis absent } \\
\hline \multicolumn{5}{|l|}{ Stage Ta } \\
\hline Low Grade & $<3$ years & 0.11 & $11 \%$ & $0.42 \%$ \\
\hline Size $4 \mathrm{~cm}$ & $>3$ years & 0.90 & $89 \%$ & $3.58 \%$ \\
\hline \multicolumn{5}{|l|}{ Cis absent } \\
\hline \multicolumn{5}{|l|}{ Stage Ta } \\
\hline High Grade & $<3$ years & 0.33 & $32 \%$ & $3.25 \%$ \\
\hline Size $2.5 \mathrm{~cm}$ & $>3$ years & 0.69 & $68 \%$ & $6.75 \%$ \\
\hline \multicolumn{5}{|l|}{ Cis absent } \\
\hline \multicolumn{5}{|l|}{ Stage T1 } \\
\hline Low Grade & $<3$ years & 0.24 & $24 \%$ & $0.94 \%$ \\
\hline Size $0.7 \mathrm{~cm}$ & $>3$ years & 0.78 & $76 \%$ & $3.06 \%$ \\
\hline \multicolumn{5}{|l|}{ Cis absent } \\
\hline \multicolumn{5}{|l|}{ Stage T1 } \\
\hline Low Grade & $<3$ years & 0.32 & $32 \%$ & $1.28 \%$ \\
\hline Size $2 \mathrm{~cm}$ & $>3$ years & 0.69 & $68 \%$ & $2.72 \%$ \\
\hline \multicolumn{5}{|l|}{ Cis present } \\
\hline \multicolumn{5}{|l|}{ Stage T1 } \\
\hline High Grade & $<3$ years & 0.87 & $86 \%$ & $8.65 \%$ \\
\hline Size $7 \mathrm{~cm}$ & $>3$ years & 0.14 & $14 \%$ & $1.35 \%$ \\
\hline Cis present & & & & \\
\hline
\end{tabular}


Looking Table 7, we note that the variable Histological Grade has great influence in the prediction of the risk of progression: patients with low grade tumors showed lower likelihood of progression while those with high grade presented a higher probability. Analyzing patients with Carcinoma in situ (Cis), we note that these have higher chances of tumor progressing. Therefore the presence of Carcinoma in situ worsens the prognosis of the patient, as was expected.

In this way, the results of the new system based on fuzzy rules were more optimistic and more consistent with the reality of the patients.

\section{Conflicts of Interest}

The authors declare no conflicts of interest regarding the publication of this paper.

\section{References}

[1] Rodrigues, N. (2008) Urologia Prática. Editora Roca, São Paulo.

[2] Matheus, W.E. (2007) Carcinoma urotelial invasivo de bexiga: Primário versus progressivo: Análise multicêntrica de sobrevida global. Tese de Doutorado, FCM-UNICAMP, Campinas.

[3] Damião, R. (1999) Guia Prático de Urologia. SBU—Sociedade Brasileira de Urologia, São Paulo.

[4] Chen, L., Peng, J., Zhang, B. and Li, S.G. (2017) Uncertain Programming Model for Uncertain Minimum Weight. Journal of Intelligent Manufacturing, 28, 625-632. https://doi.org/10.1007/s10845-014-1009-1

[5] Liu, B. (2015) Uncertainty Theory. Vol. 4, Springer, Berlin.

[6] Zadeh, L.A. (1965) Fuzzy Sets. Information and Control, 8, 338-353. https://doi.org/10.1016/S0019-9958(65)90241-X

[7] Barros, L.C. and Bassanezi, R.C. (2015) Tópicos de Lógica Fuzzy e Biomatemótica. Vol. 5, Colecão textos didáticos, UNICAMP/IMECC, Campinas.

[8] Bassanezi, R.C., Barros, L.C. and Lodwick, W. (2017) A First Course in Fuzzy Logic, Fuzzy Dynamical System, and Biomathematics. Vol. 347, Springer, Berlin. 